\title{
Self-heating in pulsed mode for signal quality improvement: application to carbon nanostructures-based sensors
}

\author{
O. Monereo*, O. Casals, J. D. Prades and A. Cirera \\ MIND-IN²UB, Department of Electronics, University of Barcelona, C/ Martí i Franquès 1, \\ E-08028 Barcelona, Spain \\ *Corresponding author e-mail: omonereo@el.ub.edu. \\ Other authors e-mails: O. Casals (ocasals@el.ub.edu), J.D. Prades (paㄹes@el.ub.edu), A.Cirera \\ (acirera@el.ub.edu).
}

\begin{abstract}
.
Sensor signal instability and drift are still unresolved challenges in conductometric gas sensors. Here, the use of self-heating effect to operate a gas sensor in a pulsed temperature modulation mode (pulsed self-heating operation) is presented as an effective method to enhance signal stability and reduce consumption figures down to a few $\mu \mathrm{W}$. The sensor operation temperature was pulsed periodically between two levels, obtaining two different sensing states from one single device driven with self-heating, i.e. free of heater. The signal differences between both operating points correlated well with gas concentrations and displayed no drift. This methodology is exemplified with a thorough study of the response of carbon nanofibers to humidity. Specifically, after analyzing the influence of the pulse characteristics (i.e. temperature variation, pulse period and pulse duty cycle) on the sensor performance, thumb rules to select suitable pulsing conditions are provided. The methodology is successfully extended to other target gases, such as $\mathrm{NO}_{2}$ and $\mathrm{NH}_{3}$. Finally, its implementation in a real-time sensing system with low computational requirements is demonstrated and discussed in detail.
\end{abstract}

Keywords: self-heating, low power consumption, high stability, pulsed sensing operation, conductometric gas sensor, nanomaterials.

\section{Highlights:}

- Pulsed self-heating operation is a simple and powerful methodology to improve the signal quality of a conductometric sensor.

- Pulsed self-heating operation reduces power consumption to the range of $\mu \mathrm{W}$, without the need of incorporating heating elements.

- Sensor signal can be systematically improved by understanding the role of pulsing temperature, period and duty cycle, and then optimizing these parameters.

- For long term operation, the sensor response was found to be stable after 20 hours of continuous operation.

- The required signal processing is simple enough to be implemented in real time systems with low computing power. 


\section{Introduction}

Sensor instability is an usual, still unsolved, issue in conductometric gas sensing devices [1]. Usually, the transduction mechanisms of conductometric sensors rely on complex chemical interactions that can modify the sensing material properties. Such chemical modifications [5] (that include formation of surface complexes [2], molecule migration [3], surface poisoning with strong analyte adsorption [4-6], and gas diffusion inside the material [7]) can cause non-reversible changes of the sensor resistance. Additionally, the device structure itself can evolve during operation, suffering structural [8,9] and phase [10] transformations of the sensing layer, or degradation of the contacts [11] and heating elements [12], leading to permanent sensor modifications. All these effects can deteriorate the sensing capacity causing signal drift, baseline offsets, decay of sensing response or conductivity loses. Typically, in order to compensate these issues and prevent false readings, tedious periodic sensor calibration is required.

Improvements in baseline stability and reversibility can also be obtained by modifying the operation conditions. Traditionally, this means (1) modulating the sensor temperature [13-15] or (2) applying other energy sources as ultraviolet light [16] or visible light [17]. However, these techniques increase the power budget (typically $100 \mathrm{~mW}$ to $1 \mathrm{~W}$ in commercial devices [18]) and the device complexity and cost. Today, the most efficient designs can reduce power consumption down to tens of mW (with state-of-the-art micro heaters [19] or LEDs [20]).

A cost-effective alternative [21] is the use of the Joule effect or the so-called self-heating effect $[6,20,22]$. In this mode of operation, the power dissipated by the probing current/voltage applied to measure the resistance heats up the sensor material. The self-heating effect was first observed in one single $\mathrm{SnO}_{2}$ nanowire [23,24], obtaining devices operated with less than $10 \mu \mathrm{W}$. During the last years, self-heating was used in devices formed by one single nanostructure $[25,26]$ or a few ordered nanostructures [23]. The complexity of these configurations hampered the widespread use of this approach. Recent reports demonstrate that the self-heating effect also occurs in large arrays of randomly deposited nanofibers [21], achieving power savings similar to those observed in highly ordered nanostructures $(\sim \mu \mathrm{W})[23,24]$ with the advantage of a less complex fabrication.

Temperature modulation was used in the past to enhance the selectivity towards the desired target gases $[22,27]$ or to (partially) regenerate the sensor surface to the initial state by means of temperature cycling operation [28]. In addition, the application of temperature cycles is compatible with multidimensional data processing techniques (e.g. principal component analysis, PCA or/and linear discriminant analysis, LDA [29,30]) as the different spectra of temperatures applied to the sensor could be considered as a multidimensional stream of data for a particular odor.

In this article, self-heating and pulsed temperature modulation are combined to obtain two signals corresponding to two operation states (i.e. low and high temperature). The results demonstrate, that the combination of this two operation points is enough to detect and correct signal instabilities and drift.

Here, the advantages of pulsed self-heating operation are exemplified using carbon nanofibers [31,32] (from now on CNFs) as the active sensing material. CNFs are a carbon allotrope with sensing characteristics similar to carbon nanotubes and graphene [32-36] (e.g. low temperature gas sensing, below $100^{\circ} \mathrm{C}$ ). 
In the following article, the role of the pulsing characteristics on the sensor performance is analyzed in detail for humidity sensing. The method is then extended to other gases and implemented in a real-time sensing system. All this demonstrates that pulsed self-heating operation is a convenient strategy to improve signal quality while keeping low the power and cost budget in simple, heater-free, devices.

\section{Materials and methods}

Sensor platforms formed by interdigitated platinum electrodes (IDE) over a ceramic substrate fabricated by Francisco Albero S.A. were used [37]. The sensor platform included an embedded thermoresistance and a heater. This elements were only emplyed for temperature calibration of self-heating operation (detailed information can be found elsewhere [21]) and for comparison between sensor operation at constant temperature and pulsed self-heating methodology. Commercially available CNFs, synthesized by means of CVD floating catalyst technique by Grupo Antolín S.A., were used. The fibers presented diameters ranging from 30 to $80 \mathrm{~nm}$ and lengths up to $75 \mu \mathrm{m}$. Additional details of this material can be found elsewhere [38]. CNFs were dispersed in 2-propanol at a concentration of $1 \mathrm{mg} / \mathrm{ml}$. Then, the dispersion was drop-casted over the IDE. Electrical resistance was monitored during the deposition process with a digital multimeter Agilent 34401A to assess the continuity of the film.

The electrical measurements of sensor resistance were recorded using a Keithley 2401 source meter. The same unit served as a measurement system and as a power source to activate the selfheating effects. Gas sensing experiments were conducted in a customized chamber of $15 \mathrm{ml}$ in volume. The gas flow was maintained at $200 \mathrm{ml} / \mathrm{min}$ during all the experiments. In these conditions, the gas chamber can be fully flushed five times in less than 20 seconds. Reference gaseous atmospheres were provided by several independent mass flow controllers blending dry $\mathrm{N}_{2}$, synthetic air (SA, $79 \%$ of $\mathrm{N}_{2}$ and $21 \%$ of $\left.\mathrm{O}_{2}\right), \mathrm{NH}_{3}(100 \mathrm{ppm}$ in $\mathrm{SA})$ and $\mathrm{NO}_{2}(10 \mathrm{ppm}$ in $\mathrm{SA}$ ). Constant relative humidity (from now on $\mathrm{RH}$ ) levels were obtained by bubbling dry SA into deionized water (relative humidity obtained at a constant temperature of $25{ }^{\circ} \mathrm{C}$ at a pressure of 1 atm).

\subsection{Signal response definition}

In the presented work, the sensors were operated using two methodologies: at constant operation temperature (for comparison purposes) and pulsed self-heating mode (see Fig. 1). The first method implies using a single operation temperature during all the experiment (see Fig. 1(a)). In this case, the sensor response (from now on, classic sensor response or $S_{\text {classic }}$ ) was defined as $S_{\text {classic }}(\%)=100 \cdot\left(R-R_{o}\right) / R_{o}$, where $R$ is the steady resistance signal in each exposure to gas and $R_{o}$ is the baseline value of sensor resistance. For the second method, the pulsed self-heating mode, the sensor temperature was pulsed between two states by applying two DC voltage levels with a constant period (from now on $T_{p}$ ) (see Fig. 1(b)). Different measurements were also performed varying the pulse duty cycle (from now on, $D$ ). $D$ was defined with respect to the high temperature state $(D=10 \%$ corresponds to $10 \%$ of the period at high temperature and $90 \%$ at low temperature). Using the pulsed methodology, the sensing response was no longer defined directly in terms of the sensor resistances but in relation to the difference of resistance between both sensing states (from now on $\Delta R$ ), extracted as the difference of the upper envelope of the resistance signal (corresponding to the lower temperature state) and the lower envelope of the resistance signal (corresponding to the higher temperature state): 
$\Delta R=$ Upper Envelope - Lower Envelope (see Fig. 1(b)). Therefore, the sensor response was defined as $S_{\Delta R}(\%)=100 \cdot\left(\Delta R-\Delta R_{o}\right) / \Delta R_{o}$, where $\Delta R$ is the steady difference of resistance in presence of gas between the high and low temperature states and $\Delta R_{o}$ is the baseline difference of resistance between the high and low temperature states.

(a)

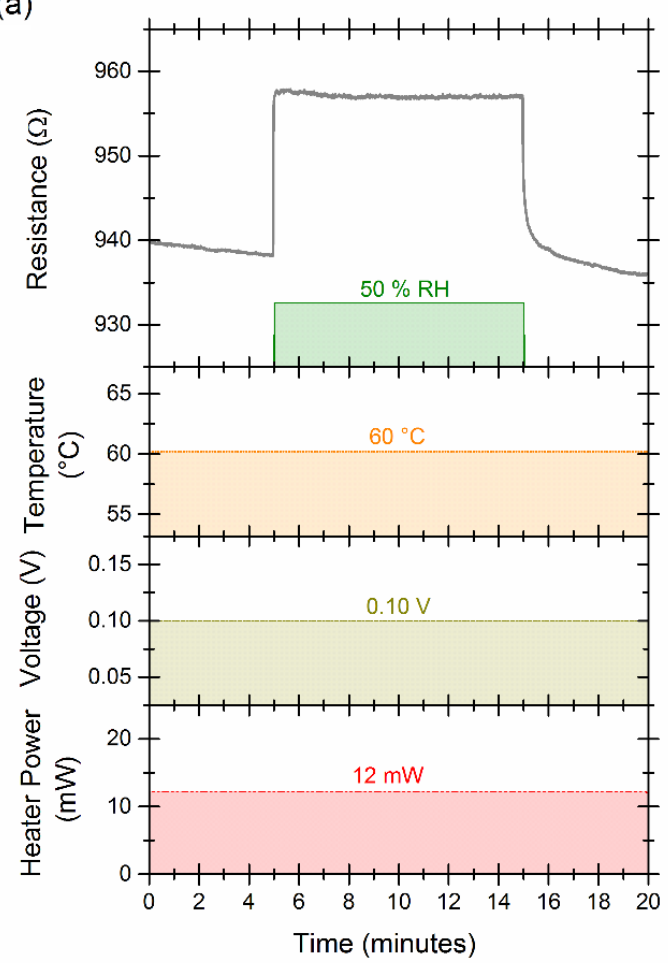

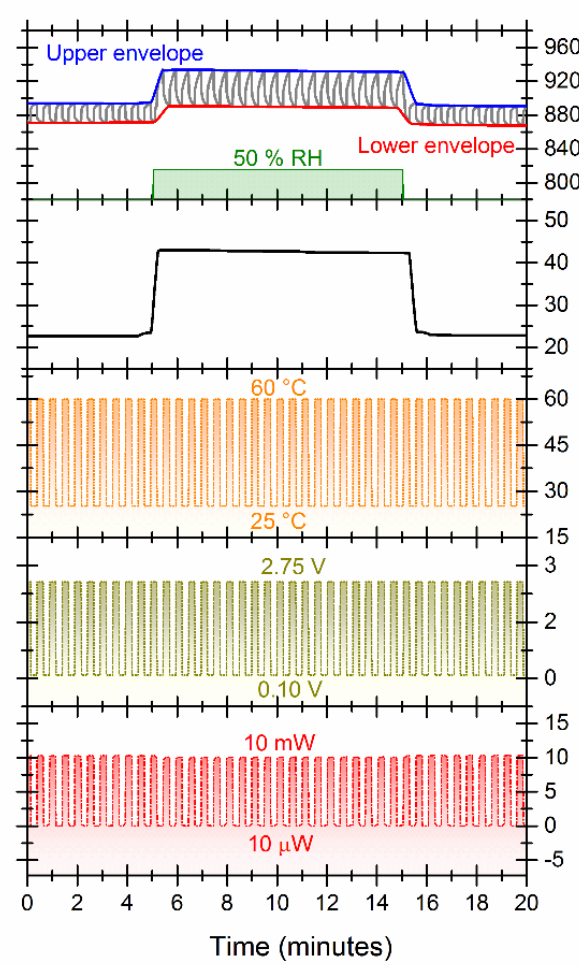

(b)

Fig. 1 Comparison between (a) classic sensor operation working at constant temperature $\left(60{ }^{\circ} \mathrm{C}\right.$, $12 \mathrm{~mW}$ ) and (b) pulsed self-heating operation, where two temperatures are used $\left(25^{\circ} \mathrm{C}, 10 \mu \mathrm{W}\right.$; $60{ }^{\circ} \mathrm{C}, 10 \mathrm{~mW}$ ) with $T_{p}=60$ seconds and $D=50 \%$. Both sensors were exposed to pulses of 50 $\%$ of RH during 10 minutes. From the upper and lower envelopes, a new signal $(\Delta R)$ can be extracted.

\section{Results \& discussion}

\subsection{Intrinsic sensor signal instability}

Conductometric sensor signals usually present signal instabilities due to several phenomena occurring at the sensor active material or in the device structure. Fig. 2(a) shows the typical resistance record of CNFs at a constant temperature. At room temperature, CNFs display significant drift and poor reversibility. In fact, the signal is extremely sensitive to the previous sensor history: exposure to high humidity contents leads to signal instabilities that are not fully recovered after removing the moisture. This situation improves slightly at a higher temperature $\left(60{ }^{\circ} \mathrm{C}\right)$, but $S_{\text {classic }}$ is reduced. Fig. 2(b) shows a summary of this trade off: temperature is an effective method to reduce drift but reducing systematically the response and increasing the power consumption. Anyhow, the drift improvement is not complete until the sensor response is almost vanished $\left(T>120^{\circ} \mathrm{C}\right)$. Therefore, constant temperature excitation does not solve in full the signal instability issues. 
(a)

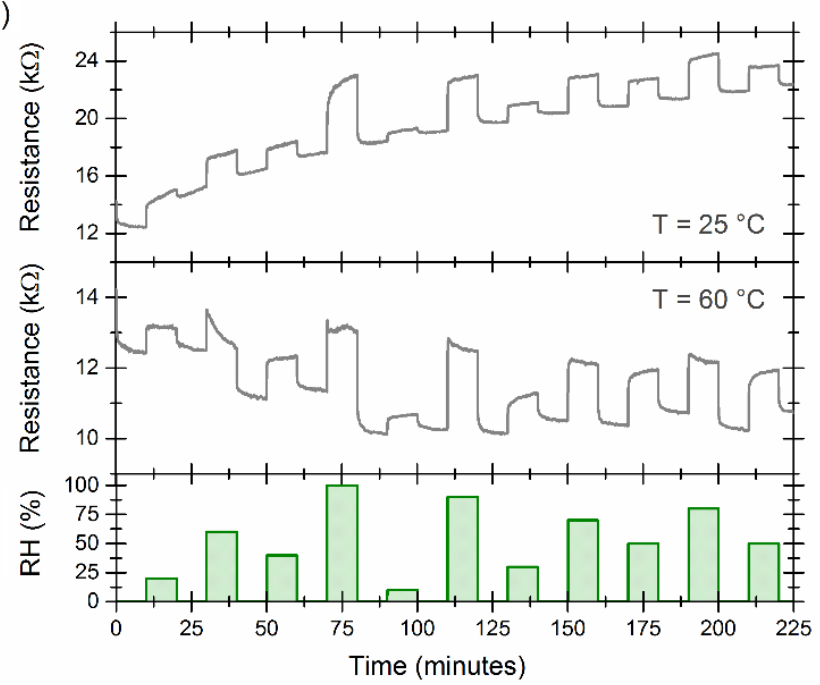

(b)

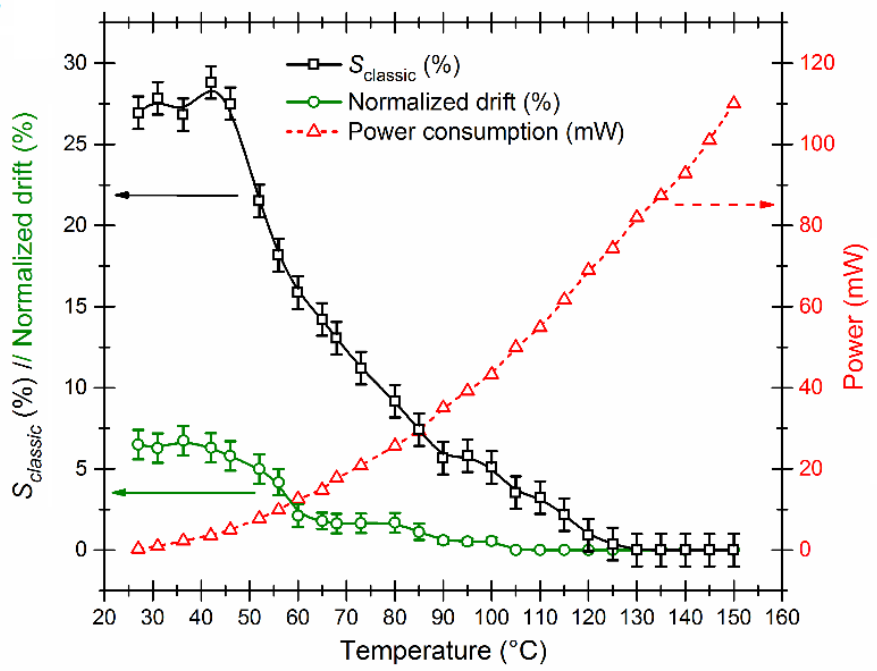

Fig. 2 (a) CNFs sensor signals obtained for a pseudo-random sequence of relative humidity concentrations at temperatures (T) of $25^{\circ} \mathrm{C}$ and $60{ }^{\circ} \mathrm{C}$. (b) Sensor response ( $\left.S_{\text {classic }}\right)$ for a pulse of $100 \%$ of relative humidity (squares), its signal drift normalized to the initial value of sensor resistance $\left(\mathrm{R}_{\mathrm{o}}\right)$ in each experiment (circles) and the power consumed by the embedded heater (triangles).

\subsection{Instability correction}

Usually, the classical signal response to gases is modulated by the operation temperature of the sensor. The adsorption of gas molecules on the sensor active material surface is dependent on the temperature (e.g. Langmuir adsorption model [39], Freundlich and Temkin isotherms [40], etc.). Following the methods described previously, sensor temperature was pulsed periodically between two levels by means of the self-heating effect (see Fig. 1 and Fig. 3(a)) in order to obtain information from the high and low temperature operation states. Since CNFs display semiconductor behavior, temperature changes lead to two sensor resistance values: lower resistance at high temperature and higher resistance at low temperature. Therefore, an upper and a lower envelope of the pulsed resistance signal could be extracted (e.g. maximum and minimum resistance values reached in each pulse step). The envelopes corresponding to both states were subtracted to obtain $\Delta R$, a signal presenting an amplitude modulation proportional to gas 
concentration (see Fig. 3(b)). This dependence is related to the differences in surface adsorption due to temperature.

Moreover, as $\Delta R$ is a combination of two sensing states originated in the same sensor, both baseline signals are completely correlated: simple subtraction seems to be enough to remove instability effects as undesired changes of the active film properties (i.e. poisoning, chemical states modification, degradation, etc.), which are simultaneous to both operation conditions. At the same time, $\Delta R$ shares the good characteristics of both envelopes: good response at low temperature and fast response at high temperature.

In essence, with a pulsed self-heating operation, two signals can be extracted from the same sensor device helping to improve the sensing characteristics dramatically (see Fig. 3(a) vs. Fig. 3(b)), without increasing the amount of system components. In contrast with sensor arrays, all signals are generated in the same device. Therefore, all of them are submitted to the same instabilities, in full correlation.
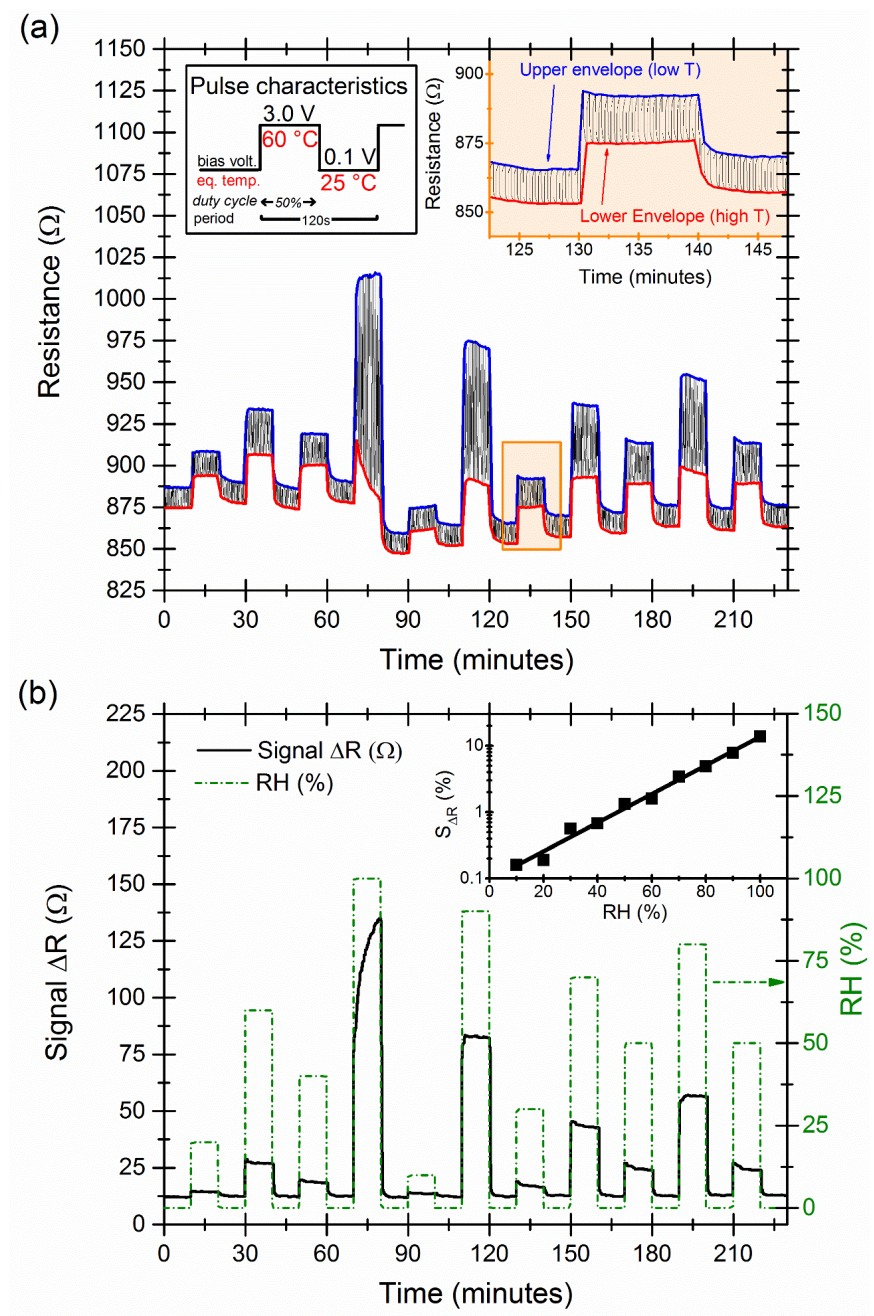

Fig. 3 (a) Pulsed CNFs sensor between $25{ }^{\circ} \mathrm{C}$ and $60{ }^{\circ} \mathrm{C}$ by means of self-heating. Signal envelopes corresponding to a high and low sensor operation point are plotted. In the upper-left inset: pulse characteristics scheme for the probing voltage, equivalent temperature is also shown. In the upper-right inset: detail of the transient CNFs signal. (b) Difference of the extracted envelopes: $\Delta R$. Inset: Response obtained from $\Delta R$ signal $\left(S_{\Delta R}\right)$. 


\subsection{Thermal influence vs. gas effects}

In self-heated systems, the temperature variation can be much faster than in their heater-driven counterparts [41]. For comparison, Fig. 4(a) shows the resistance variation in equivalent pulsed heating conditions (between $25{ }^{\circ} \mathrm{C}$ and $70{ }^{\circ} \mathrm{C}$ ), driven with self-heating and with the substrate heater. A pulse with $T_{p}=120 \mathrm{~s}$ was used to ensure full thermal stabilization. In all the tested devices, the self-heating response was almost four times faster. This is due to the much higher thermal inertia in the heater-driven system, in which the dissipated power heats not only the CNFs array, but also, the heater/substrate mass. Consequently, in heater-driven systems more power dissipation is needed for equivalent temperatures, and longer thermal stabilization times are expected.

A detailed analysis of the resistance records in self-heating operation, showed two dynamic regimes during the heating/cooling process (Fig. 4(a)): a fast initial variation (in the scale of milliseconds) followed by a slower stabilization of the signal (in the scale of seconds). The phenomena occur symmetrically both in heating and cooling cycles.

In atmospheres that are typically non-reactive for the CNFs, such as low vacuum $\left(3 \cdot 10^{-5} \mathrm{hPa}\right), \mathrm{N}_{2}$, and SA atmospheres (see Fig. 4(b)), both regimes are insensitive to the presence of one or another gas.

In contrast, in presence of humidity (25\%,50\% and $100 \%$, Fig. 5(a)), significant differences are observed in the resistance change during the slow regime (slow processes labeled as I and III in Fig. 5). The fast processes, in turn, were insensitive to humidity variations with a nearly constant resistance change (fast processes II and IV).

Therefore, the fast processes (cooling II and heating IV) are exclusively related to the temperature, and the slow processes (cooling I and heating III) correlate with the presence of gases (Fig. 5(b)). This explains why the magnitude $\Delta R$ (which is the accumulated resistance change occurred after I, II, III and IV) reflects the signal variation only dependent on the gas concentration. 
(a)

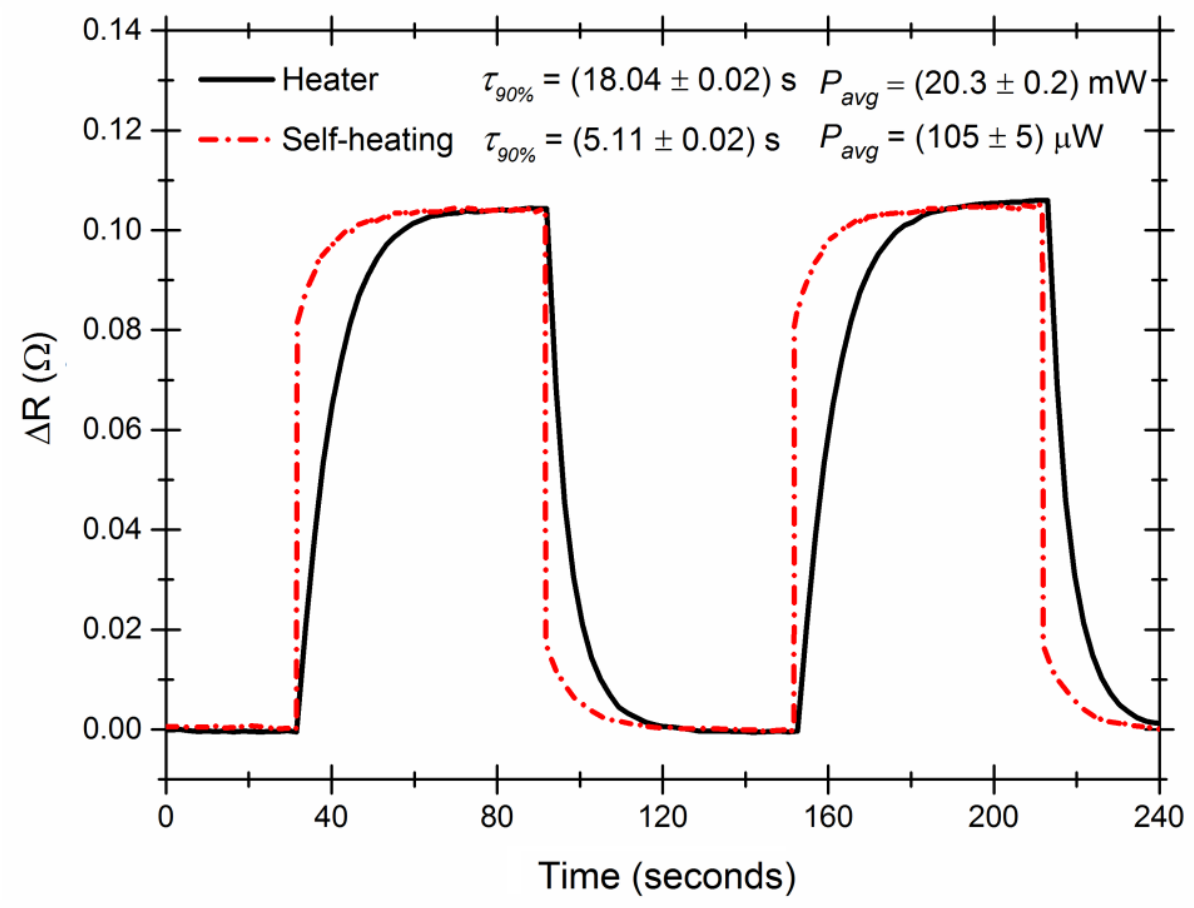

(b)

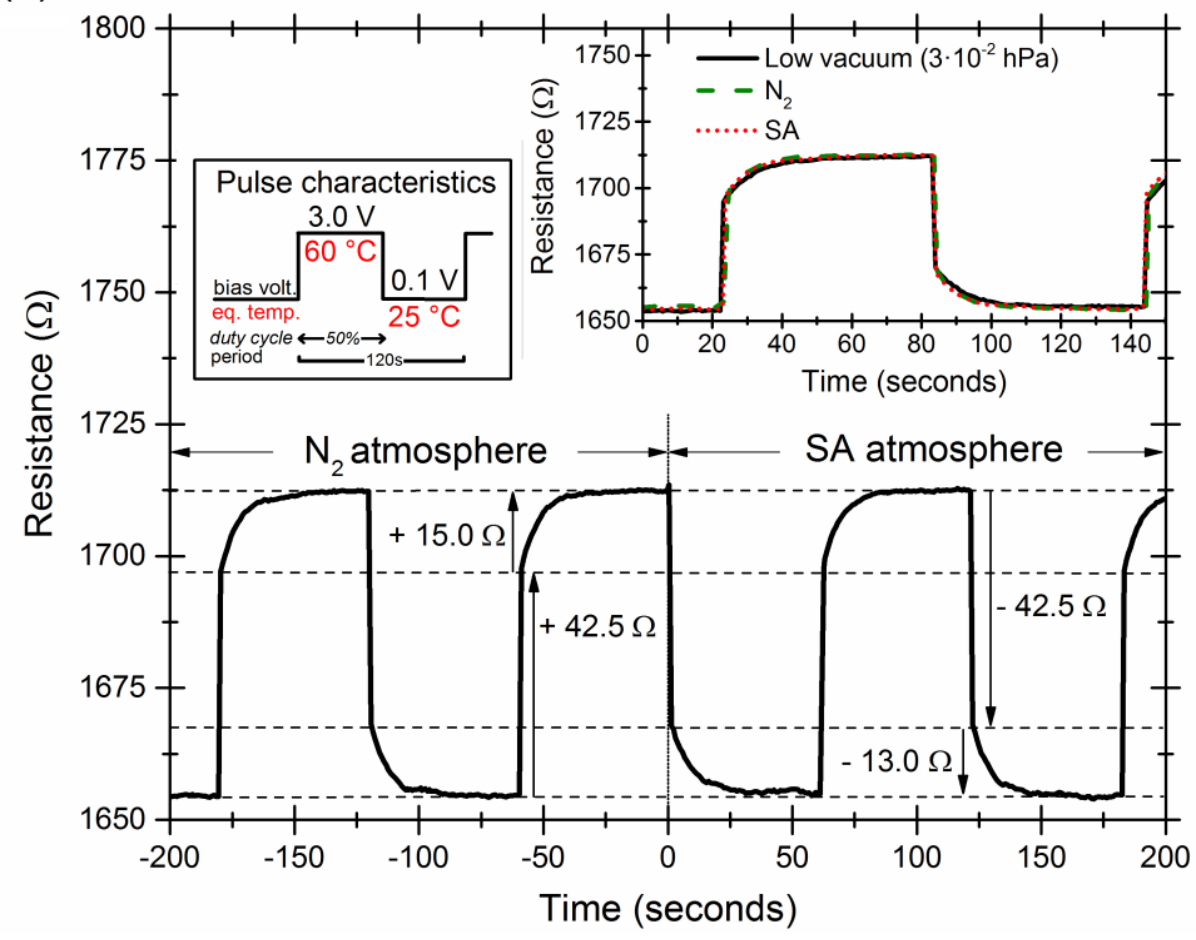

Fig. 4 (a) Relative difference of the CNFs sensor signal pulsed in equivalent conditions using the external heater and self-heating operation, the time needed to reach the $90 \%$ of the total relative change is shown $\left(\tau_{90 \%}\right)$. (b) Transient resistance signal of a pulsed CNFs sensor between $0.1 \mathrm{~V}$ $\left(25^{\circ} \mathrm{C}\right)$ and $3 \mathrm{~V}\left(60^{\circ} \mathrm{C}\right)$ in $\mathrm{N}_{2}$ and $\mathrm{SA}$ atmospheres, no change in the sensor signal is appreciable. Upper-left inset: pulse characteristics for the probing voltage, equivalent temperature is also displayed. Upper-right inset: comparison of the pulsed resistance signal $\left(25^{\circ} \mathrm{C}-60{ }^{\circ} \mathrm{C}\right)$ in vacuum $\left(3 \cdot 10^{-2} \mathrm{hPa}\right), \mathrm{N}_{2}$ and $\mathrm{SA}$ atmosphere. 
(a)
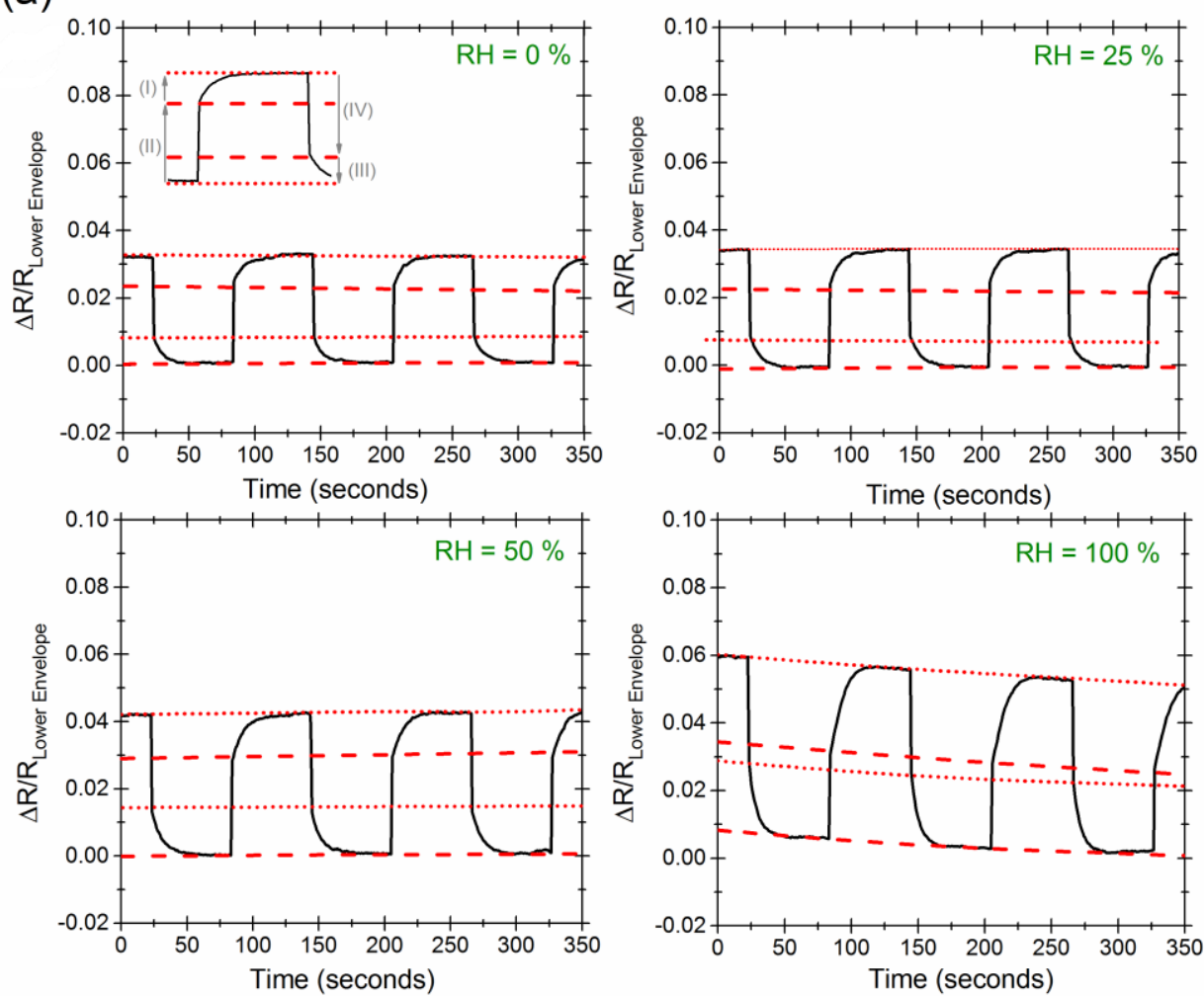

(b)

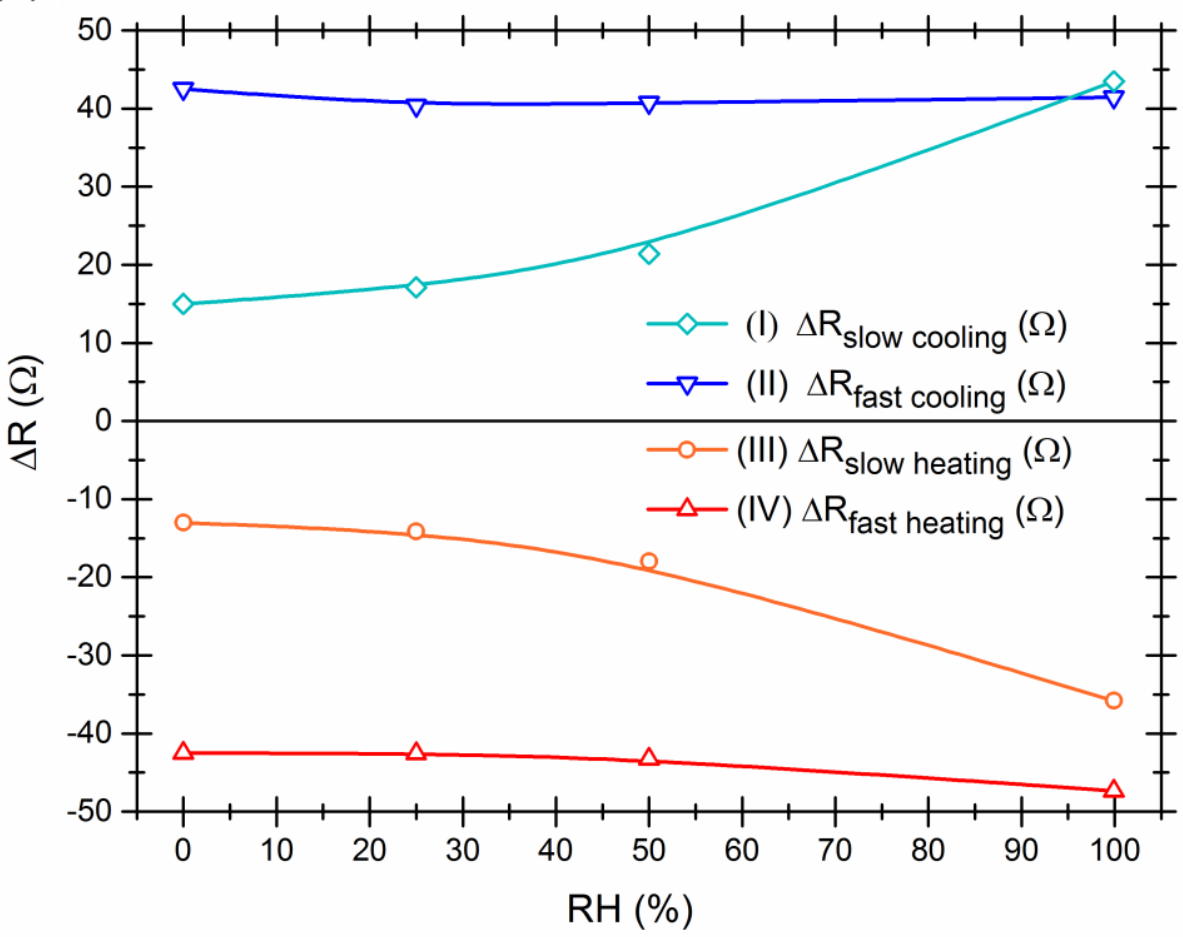

Fig. 5 (a) Transient resistance signal of a pulsed CNFs sensor between $0.1 \mathrm{~V}\left(25^{\circ} \mathrm{C}\right)$ and $3 \mathrm{~V}(60$ ${ }^{\circ} \mathrm{C}$ ) in SA atmospheres with $0 \%, 25 \%, 50 \%$ and $100 \%$ of relative humidity. Signal envelopes are displayed and normalized to the resistance corresponding to the lower envelope ( $\left.R_{\text {Lower Envelope }}\right)$. (b) $\Delta R$ corresponding to the different processes occurring during pulse: slow cooling (I) and heating (III), fast cooling (II) and heating (IV). 


\subsection{Effect of the pulsing conditions}

In order to elucidate the dependence of $\Delta R$ magnitude on the self-heating pulse conditions, the pulsed temperatures, period $\left(T_{P}\right)$ and duty cycle $(D C)$ were studied in detail for humidity sensing.

\subsubsection{Pulsed temperatures}

Fig. 6(a) shows the response to different humidity contents of a sensor pulsed between a reference temperature $\left(25^{\circ} \mathrm{C}\right.$ set with $\left.0.1 \mathrm{~V}\right)$ and different high temperature states $\left(200{ }^{\circ} \mathrm{C}, 100{ }^{\circ} \mathrm{C}, 50{ }^{\circ} \mathrm{C}\right.$ and $35^{\circ} \mathrm{C}$, set with $8 \mathrm{~V}, 5 \mathrm{~V}, 3 \mathrm{~V}$ and $1 \mathrm{~V}$, respectively). After extracting the envelopes and their difference, the $\Delta R$ signal (Fig. 6(b)) was fully stable throughout the experiment and scaled up with the relative humidity content. In general, larger $\Delta R_{o}$ values were obtained increasing the temperature difference in the pulses but also similar $S_{\Delta R}$. Thus, for this particular target gas, larger temperature spans do not lead to any particular benefit. In low temperature span measurements, a large response only to pulses of saturated humidity was detected. This behavior is attributed to a partial wetting of the sensor surface.

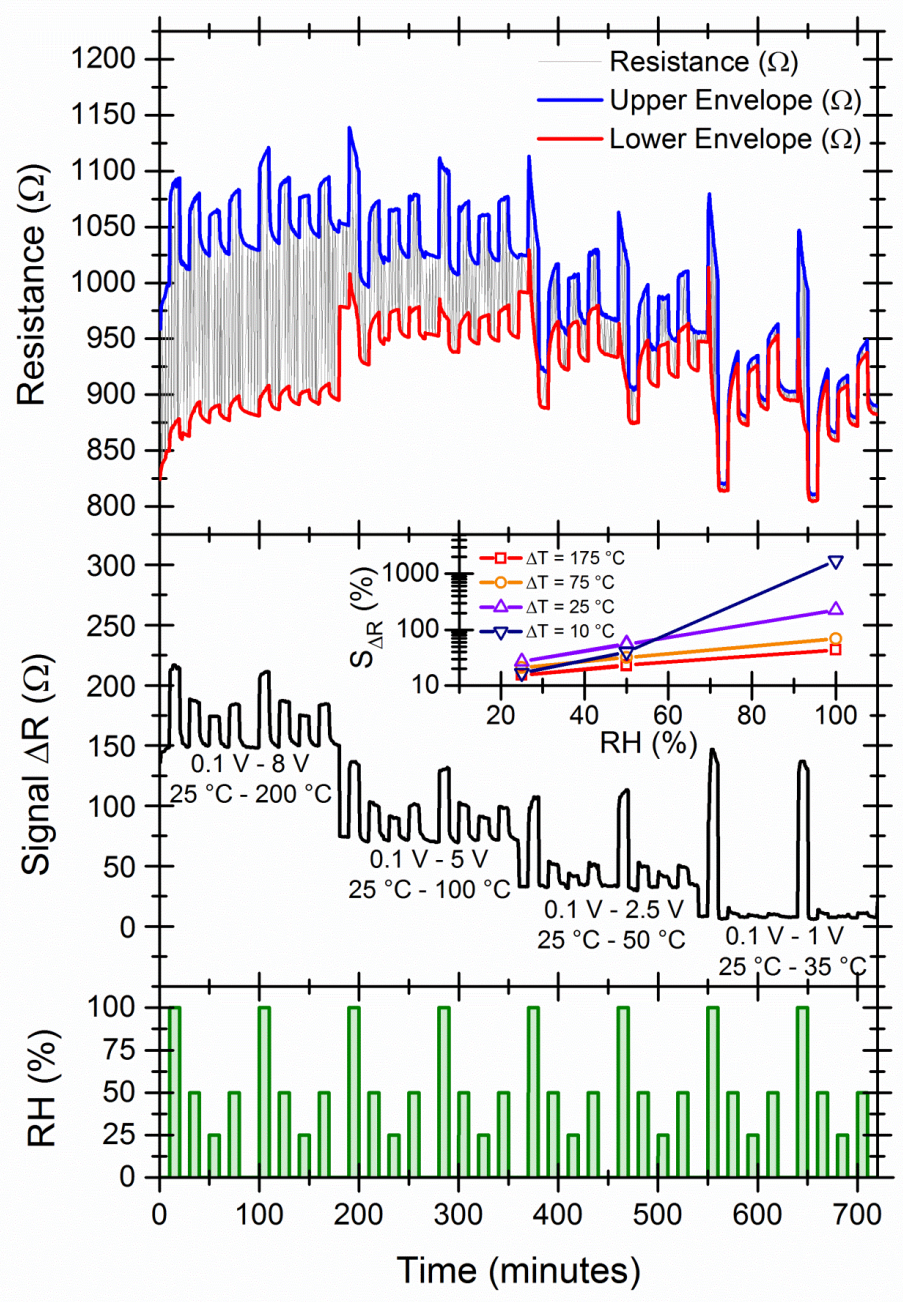

Fig. 6 Transient sensor response and $\Delta R$ obtained for a series of relative humidity pulses (100\%, $50 \%, 25 \%$ and $50 \%$ ). Sensor resistance pulsed between $25^{\circ} \mathrm{C}$ and $200{ }^{\circ} \mathrm{C}, 100{ }^{\circ} \mathrm{C}, 50{ }^{\circ} \mathrm{C}$ and $35^{\circ} \mathrm{C}$. Inset: Responses obtained from $\Delta R$ signal. 


\subsubsection{Pulse period $\left(T_{p}\right)$}

Pulsed temperature operation keeps the sensor surface swinging between two gas/surface interaction states. Such periodic transition involves the adsorption and subsequent desorption of gaseous molecules from the surface. Only for long $T_{p}$, the adsorption and desorption processes are completed reaching steady resistance values. In fast pulsing periods (with low $T_{p}$ ) adsorption and desorption are suddenly interrupted by a temperature change. Therefore, the resistance readings always correspond to surface transient states in which the sensor surface sites are not completely fill or empty (Fig. 7 (a)).

In this context, the concepts of response and recovery times are artificial and essentially related to the $T_{p}$ value of choice. According to our definition of $\Delta R$ (i.e. the difference between the envelopes, or the maximum and minimum resistance values during the hot and cold semiperiods $\left(T_{p} / 2\right)$ ), the $\Delta R$ signal is sampled once in every pulsing period and this defines the effective "response and recovery" times of the sensor system. Therefore, we could consider that the $\Delta R$ signal changes "immediately" after the temperature change, provided that there has been a change in the gas concentration.

Therefore, the period of the pulsed signal should be enough to ensure, at least, a partial gas adsorption-desorption process. In addition, it is possible to lower the pulsed period to improve the response and recovery times almost at will.

A summary of the dependence of $\Delta R$ with the pulsing period is shown in Fig. 7(b). All curves follow a behavior similar to that of a low-pass frequency filter modulated by the gas concentration: as water molecules have more time to interact with CNFs surface during each $T_{P} / 2$, $\Delta R$ increases with both the amount of humidity and with $T_{p}$. In this sense, very short periods lead to very low $\Delta R$ variations. Interestingly, the pulsed response $S_{\Delta R}$ is constant for pulse periods longer than the typical response time to humidity in constant temperature operation (e.g. $60 \mathrm{~s}$ for $100 \%$ of $\mathrm{RH}$ at $25^{\circ} \mathrm{C}$ in constant operation [21]).

Summarizing, the pulsing period $T_{p}$ determines the response and recovery times of the pulsed signal. At the same time, the pulsing period serves to adjust the $\Delta R$ variation with humidity, obtaining larger responses for longer periods, until reaching the steady response limit. All this leads to a compromise between response dynamics and response magnitude that could be used to provide some specificity over different target gases. 


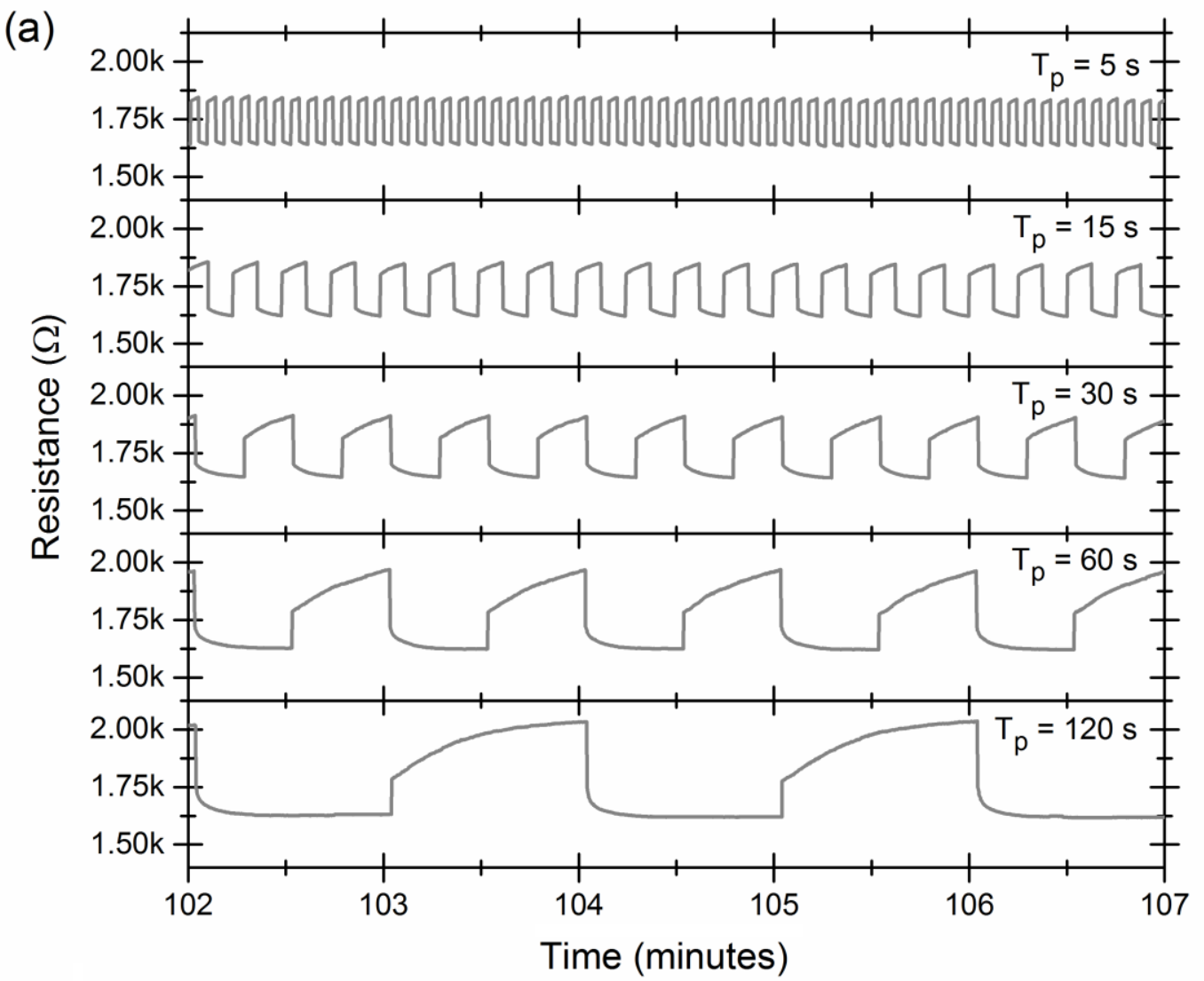

(b)

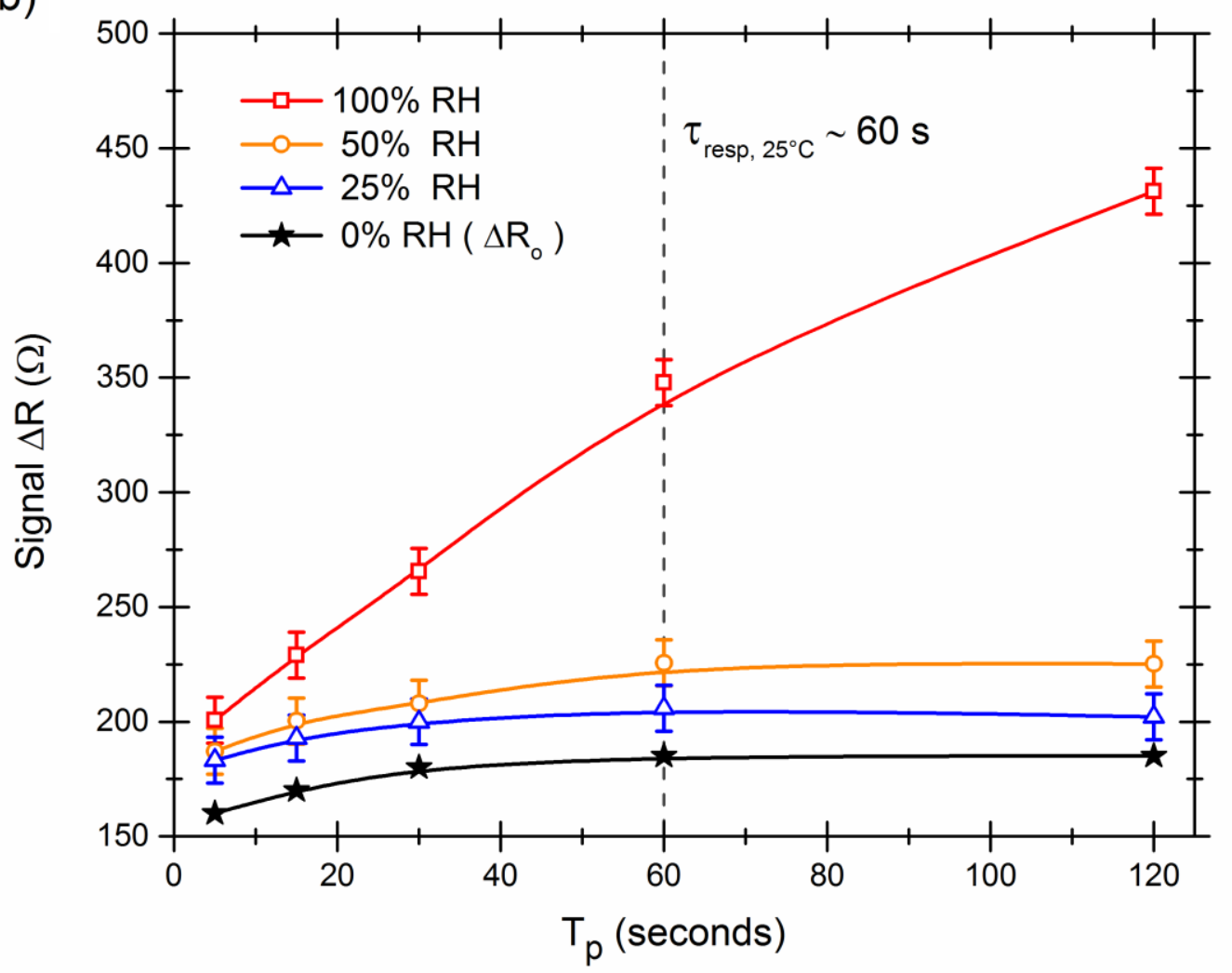

Fig. 7 (a) Detail of the transient resistance signal for pulse period of 5, 15, 30, 60 and 120 seconds in an atmosphere of $\mathrm{RH}=100 \%$. (b) Dependence of $\Delta R$ with the pulsed signal period. The response time for continuous sensing mode at $25{ }^{\circ} \mathrm{C}$ is marked with a vertical dashed line. 


\subsubsection{Pulse duty cycle (D)}

Different pulse duty cycles $D(10 \%, 30 \%, 50 \%, 70 \%$ and $90 \%)$ were tested in similar conditions (see Fig. 8). Essentially, the lower the $D$ the lesser the time the sensor remains at the higher temperature state with the benefit of reducing the power consumption. From the gas/surface interaction perspective, $D$ tailors the adsorption/desorption balance.

For a given period configuration and provided that the $D$ is large enough to ensure a quantifiable gas adsorption-desorption process between both temperature states, the shape of $\Delta R$ does not vary significantly with $D$ (see Fig. 8(b)).

Therefore, $D$ modulation offers chances to further reduce the power consumption. The average power $\left(P_{\text {avg }}\right)$ consumed in pulsed operation can be calculated as $P_{\text {avg }}=D \cdot P_{\text {high }}+(1-D) \cdot P_{\text {low }}$, where $D$ is the duty cycle of the pulsed signal, $P_{\text {high }}$ and $P_{\text {low }}$ is the average power consumed at the high and low temperature sensing condition, respectively. Since $P_{l o w}<<P_{\text {high }}$, the dependence in $P_{\text {avg }}$ approximates to $P_{\text {avg }} \approx D \cdot P_{\text {high }}$, in accordance with the results shown in Fig. 9. Consequently, $P_{\text {avg }}$ can be reduced up to two orders of magnitude varying the DC from $90 \%$ to $10 \%$ (the lowest $P_{\text {avg }}$ value obtained was $(9.58 \pm 0.02) \mu \mathrm{W}$, Fig. 9), without losing any sensing capability.

(a)

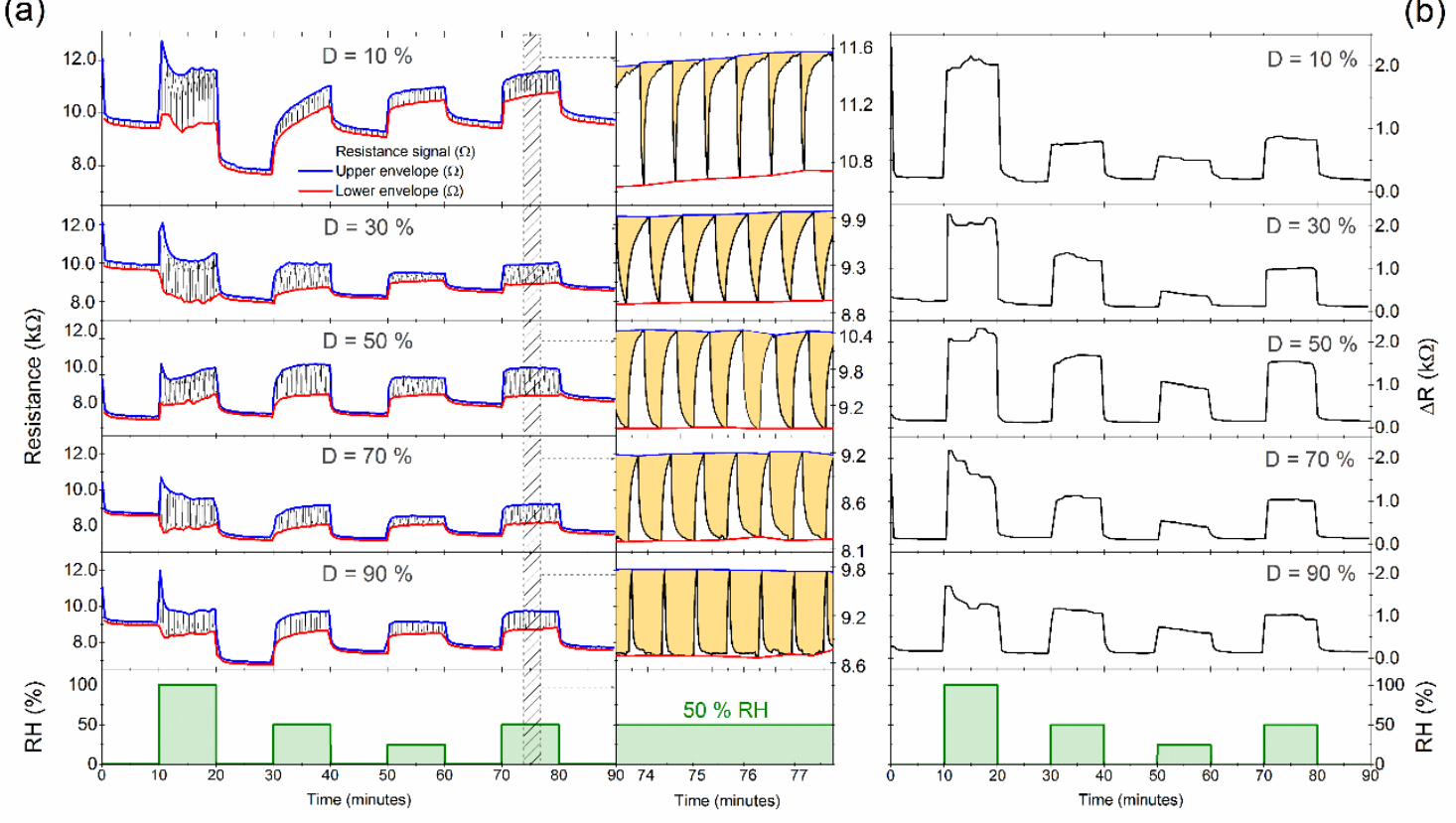

Fig. 8 (a) Pulsed self-heating measurements using voltages of $0.1 \mathrm{~V}$ and $2 \mathrm{~V}$ (corresponding to $25^{\circ} \mathrm{C}$ and $45^{\circ} \mathrm{C}$ ) with a pulse period of 1 minute in different concentrations of humidity $(100 \%$, $50 \%, 25 \%$ and $50 \%$ ). On the right, detail of the last humidity pulse at $50 \%$ of relative humidity (shaded time frame). (b) Extracted signal $\Delta R$ from the data showed at (a). 


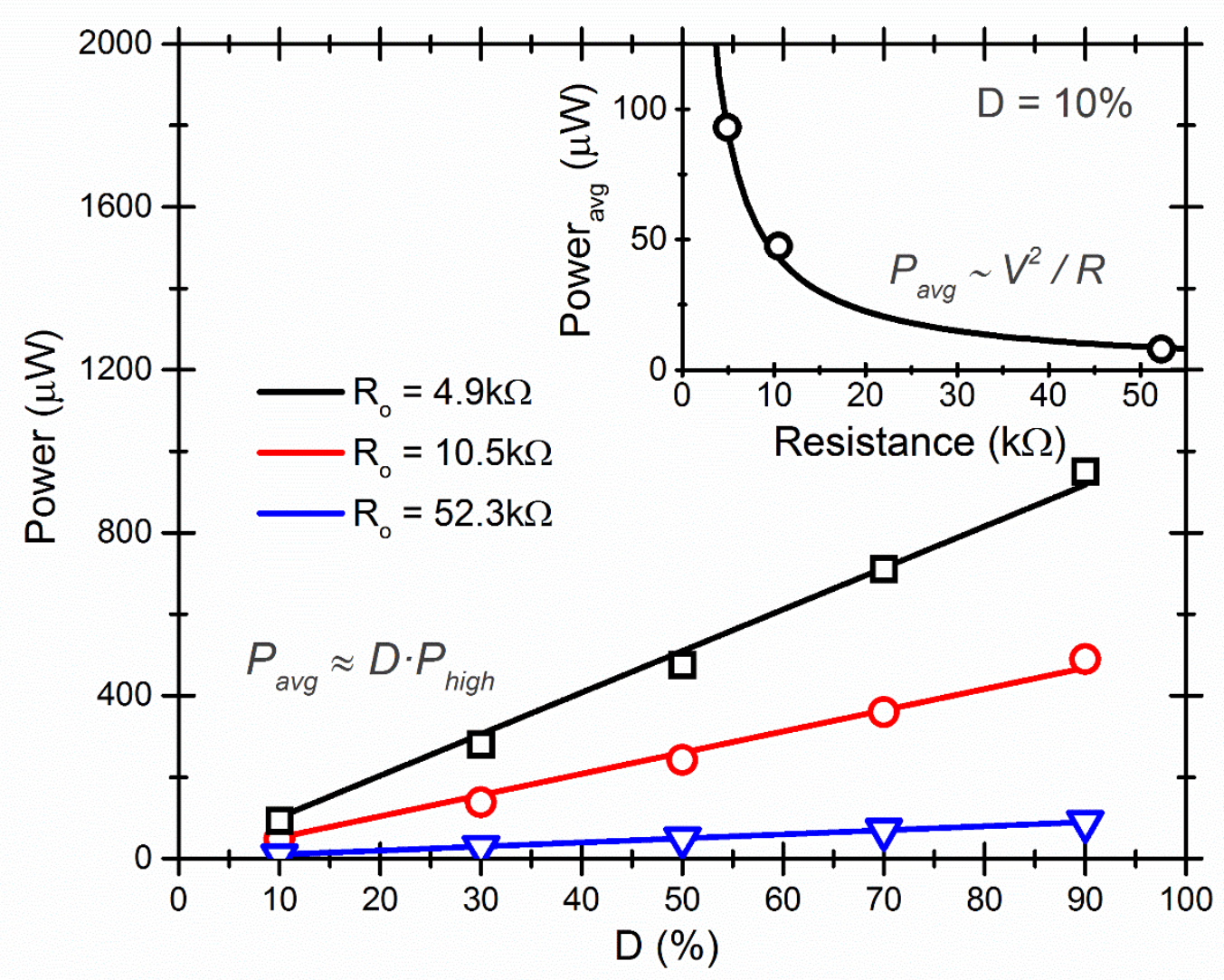

Fig. 9 Average power, $P_{\text {avg }}$, vs. duty cycle $(D)$ dependence for three sensors with different baseline resistance $R_{o}$ (the value $R_{o}$ was obtained in steady state conditions, being the sensor in a SA atmosphere during two hours). Inset: $P_{\text {avg }}$ dependence with the baseline resistance,. $R_{o}$.

\subsection{Long term stability}

The baseline stability and the sensing response repeatability were analyzed. A CNFs sensor was maintained at stable atmosphere of pure SA for 78 hours and at $50 \%$ of RH for 72 hours (Fig. 10 (a)). The resistance sensor signal drifted along the measurement due to variations of the ambient temperature. In contrast, the signal $\Delta R$ was found to reduce the deviation of the sensor signal by a 10 factor for both the SA and with $50 \%$ of RH. A humidity test with RH concentrations of 15 $\%, 50 \%, 75 \%$ and again $50 \%$ was repeated during 66 hours. The $\Delta R$ magnitude showed an initial stabilization period of about 15 hours. After that, the responses were sufficiently stable to discriminate each concentration. In summary, the pulsed self-heating methodology presents a highly repeatable behavior without losing sensing capabilities. 
(a)

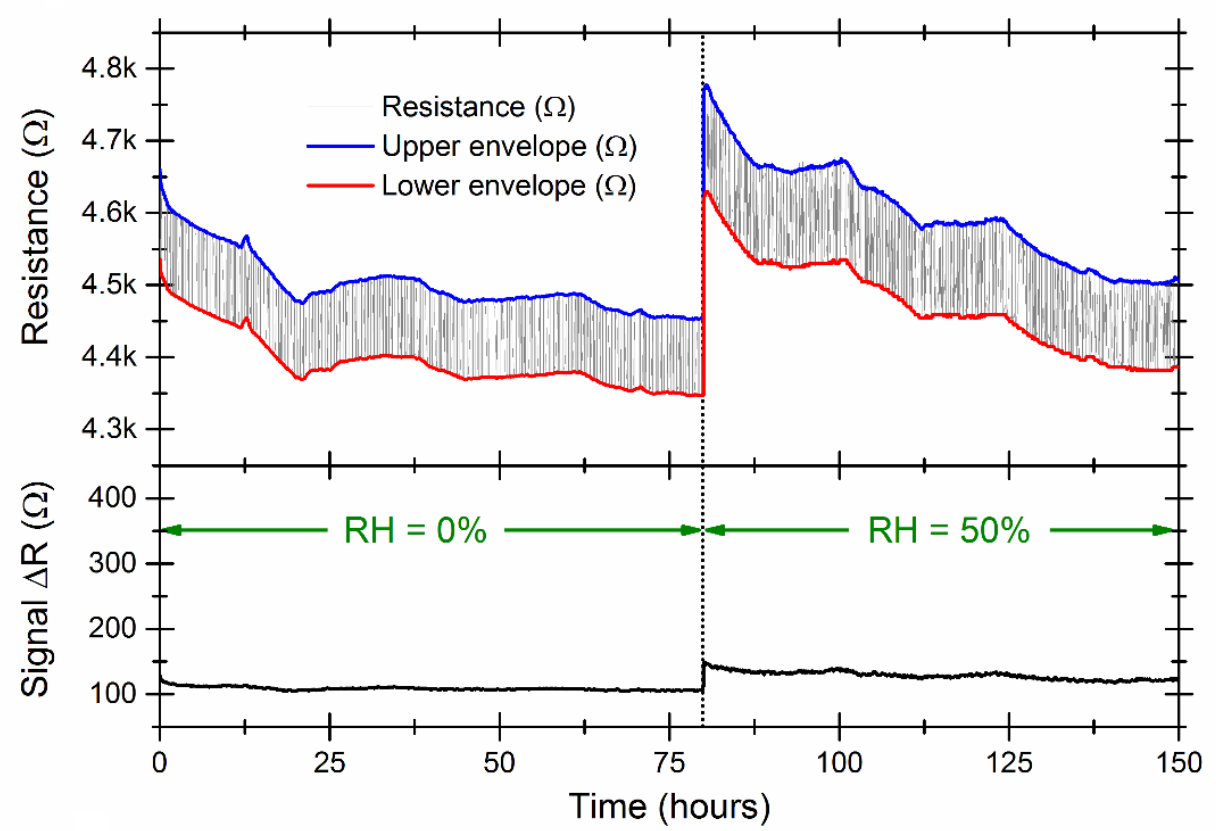

(b)

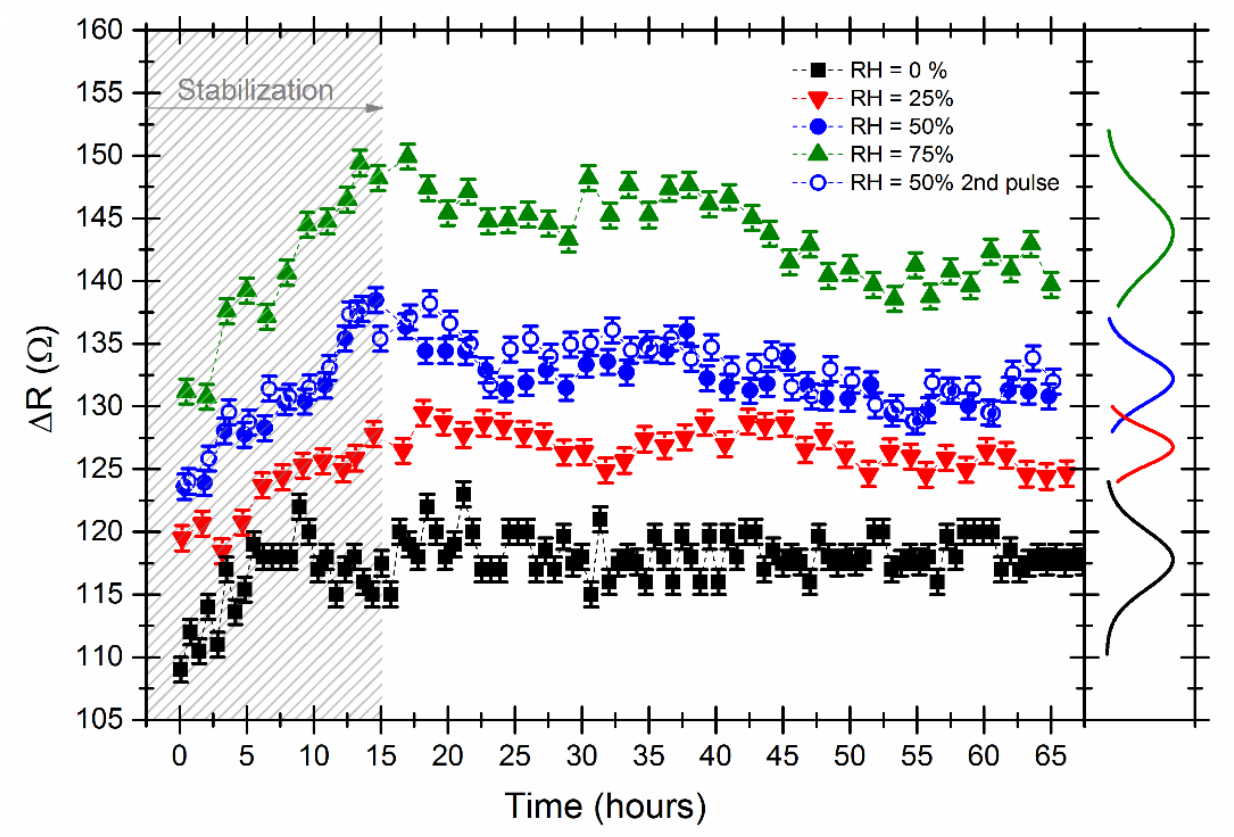

Fig. 10 (a) Long term stability study for a pulsed self-heated CNFs sensor for 150 hours (78 hours at pure SA atmosphere and 72 hours at $50 \%$ of relative humidity). Resistance and $\Delta R$ signal represented with same span. (b) Repeatability of the $\Delta R_{o}(0 \%$ of $\mathrm{RH})$ and $\Delta R$ magnitude to pulses of humidity $(25 \%, 50 \%, 75 \%$ and $50 \%$ of $\mathrm{RH})$, the gas test sequence was repeated uninterruptedly during 67 hours. On the right: Gaussian distributions fitted to the histograms of $\Delta R$ measurements at each concentration.

\section{6. $\mathrm{NO}_{2}$ and $\mathrm{NH}_{3}$ pulsed sensing}

Carbon materials, such as CNFs, are also sensitive to other gases such as $\mathrm{NO}_{2}$ and $\mathrm{NH}_{3}$ [32]. In order to prove that the pulsed self-heated methodology is suitable to sense gases other than water vapor, experiments with $\mathrm{NO}_{2}$ and $\mathrm{NH}_{3}$ were conducted at different pulsing temperatures 
(reference temperature at $25^{\circ} \mathrm{C}$ and high temperature states at $30{ }^{\circ} \mathrm{C}, 35^{\circ} \mathrm{C}, 45^{\circ} \mathrm{C}, 70{ }^{\circ} \mathrm{C}$ and 80 $\left.{ }^{\circ} \mathrm{C}\right)$. Fig. 11 shows that the benefits in signal stability are also obtained in presence of $\mathrm{NO}_{2}$ and $\mathrm{NH}_{3}$. Moreover, the differences in $\Delta R$ response to $\mathrm{NO}_{2}$ and $\mathrm{NH}_{3}$ are much larger at higher temperature variation during the pulse. Therefore, the use of different pulsing conditions partially modifies the selectivity towards different gases, opening the door to further investigations on the role of pulsed self-heating in gas selective-sensing.

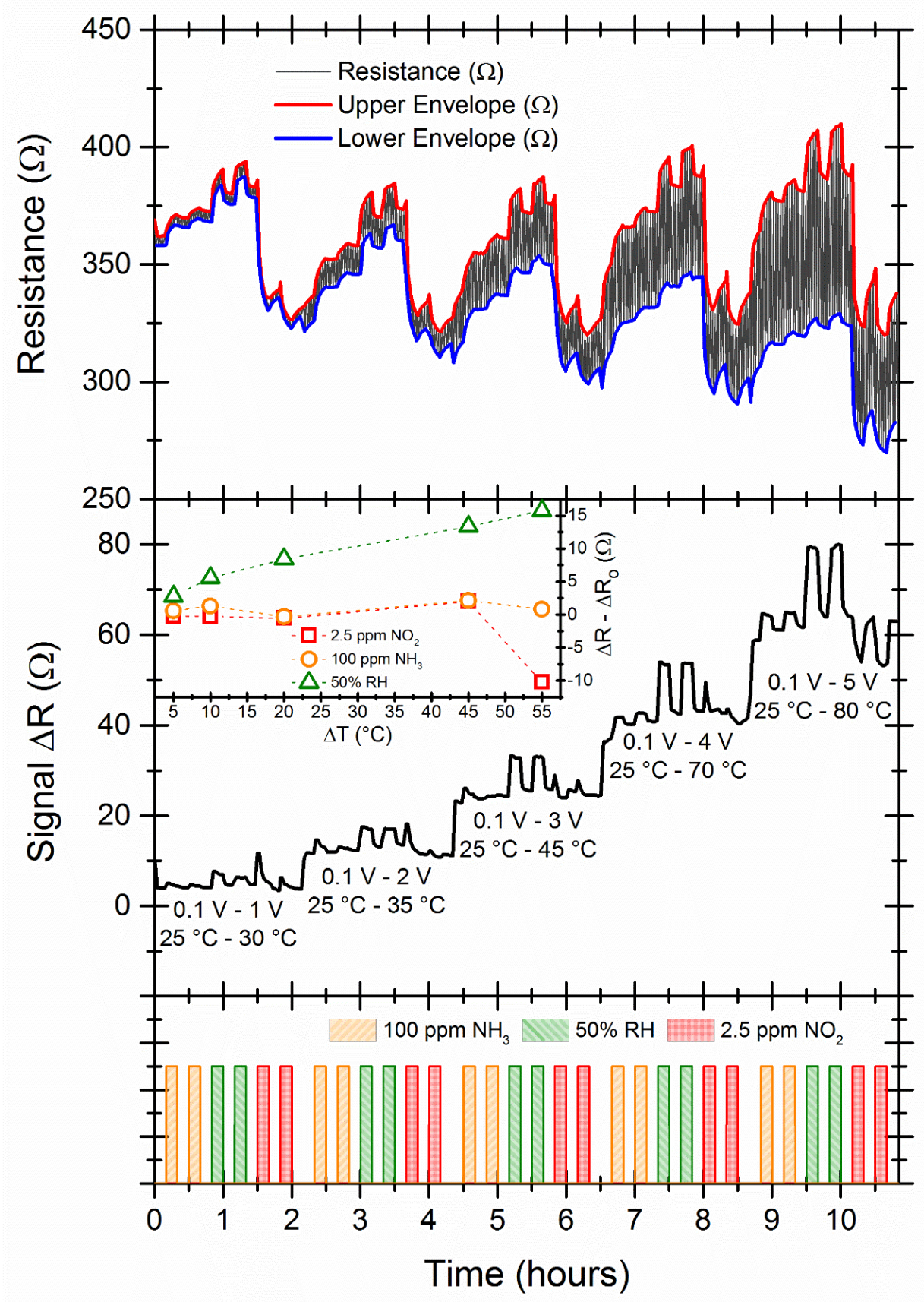

Fig. 11 Resistance signal and $\Delta R$ for five tests of $100 \mathrm{ppm}$ of $\mathrm{NH}_{3}, 50 \%$ of $\mathrm{RH}$ and $2.5 \mathrm{ppm}$ of $\mathrm{NO}_{2}$. Test temperatures between room temperature $\left(25^{\circ} \mathrm{C}\right)$ and $30{ }^{\circ} \mathrm{C}, 35^{\circ} \mathrm{C}, 45^{\circ} \mathrm{C}, 70{ }^{\circ} \mathrm{C}$ and $80{ }^{\circ} \mathrm{C}$. 


\subsection{Implementation in real environments}

The results presented so far relay on the processing of the pulsed resistance values to extract the $\Delta R$ signal. In this section we show that the $\Delta R$ calculation is a very simple procedure that could be implemented in an embedded microcontroller, with low computing power.

A system to extract the $\Delta R$ magnitude should carry out the following tasks:

1. set the probing voltage to the high temperature operation point,

2. wait for a settling time, defined by $T_{d} \cdot D$, to reach the high temperature state

3. acquire one measurement corresponding to one data point of the lower envelope signal $\left(R_{h}\right)$

4. set the probing voltage to the low temperature operation point,

5. wait for the setting time, defined by $T_{d} \cdot(1-D)$, to reach the low temperature state

6. acquire one measurement corresponding to one data point of the upper envelope signal $\left(R_{l}\right)$

7. Calculate one signal sample as $\Delta R=R_{l}-R_{h}$ with the last pair of data values acquired.

8. Repeat from 1 .

With this algorithm, no filtering is needed to extract the envelopes and no large data buffers are required: only the difference between two consecutive data points is calculated.

In order to exemplify the feasibility of implementing such approach in a real-time system, a LabVIEW $^{\circledR}$ software was designed to pulse the sensor temperature with a source-meter, to acquire the sensor resistance values and to compute the $\Delta R$ signal. The software also allowed us to change the pulsed conditions (high and low pulsing voltage levels, pulse period and pulse duty cycle) in real time during the measurements. Fig. 12 (a)-(c) shows the effect of the pulse conditions of the real time signal extracted from the sensor, which are essentially the same issues discussed in the previous sections. To prove the capability of the system to detect ambient gas variations in real time, the sensor was kept in an ambient atmosphere and exposed to human breath Fig. 12 (d), displaying fast responses (less than $1 \mathrm{~s}$ ) full signal recovery, no drift with power consumption of less than $1 \mathrm{~mW}$.

In summary, the computing power needed to perform the described tasks should be compatible with sensor systems operating at low energy, which could be assured because of the low power, heater-free, operation of the sensor device. 
(a)

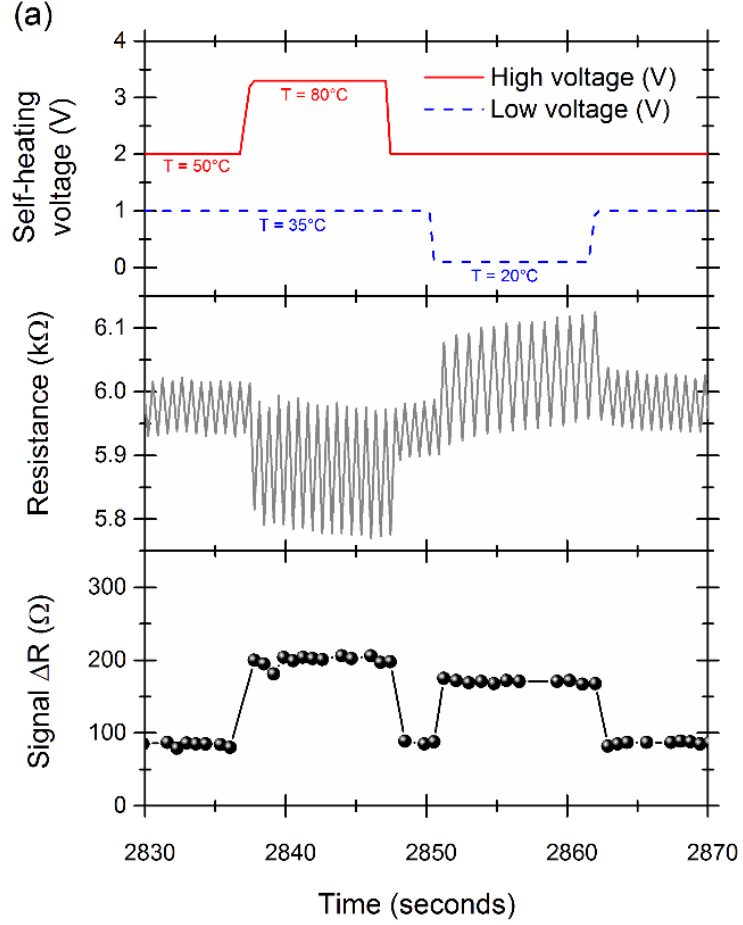

(c)

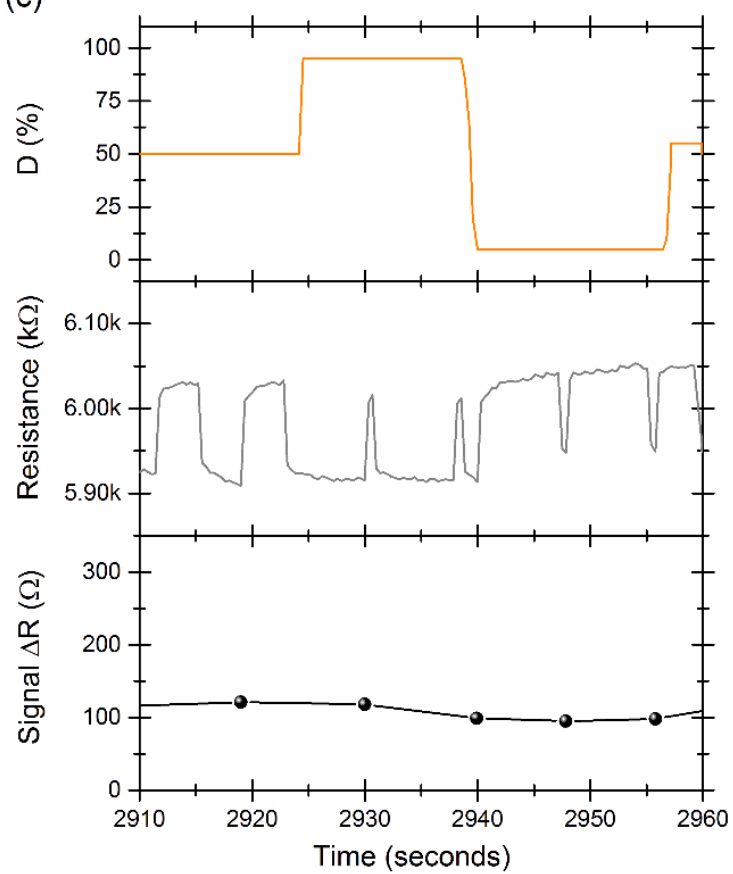

(b)

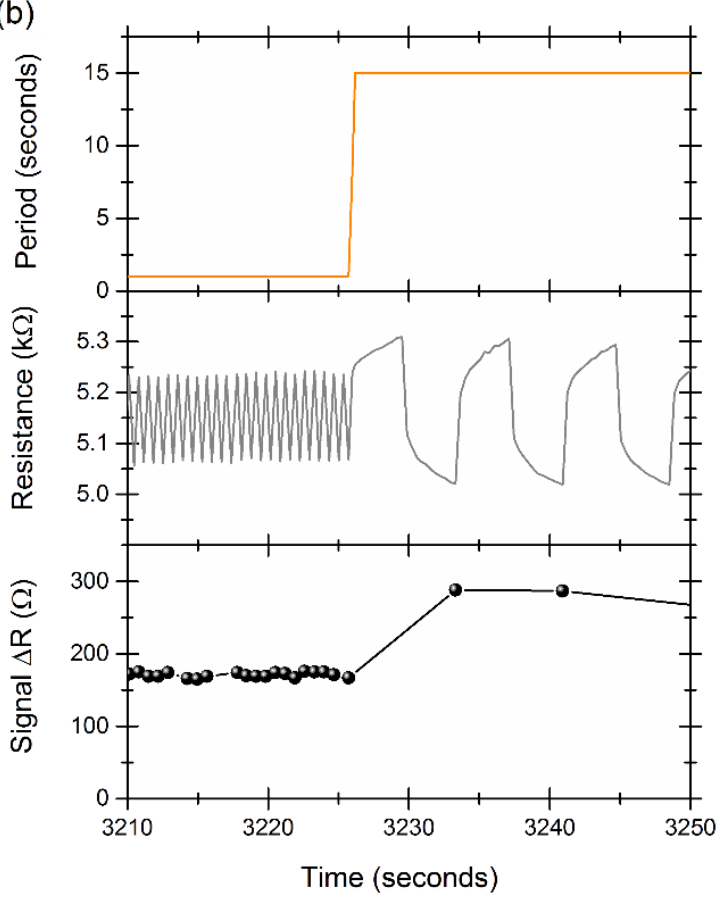

(d)

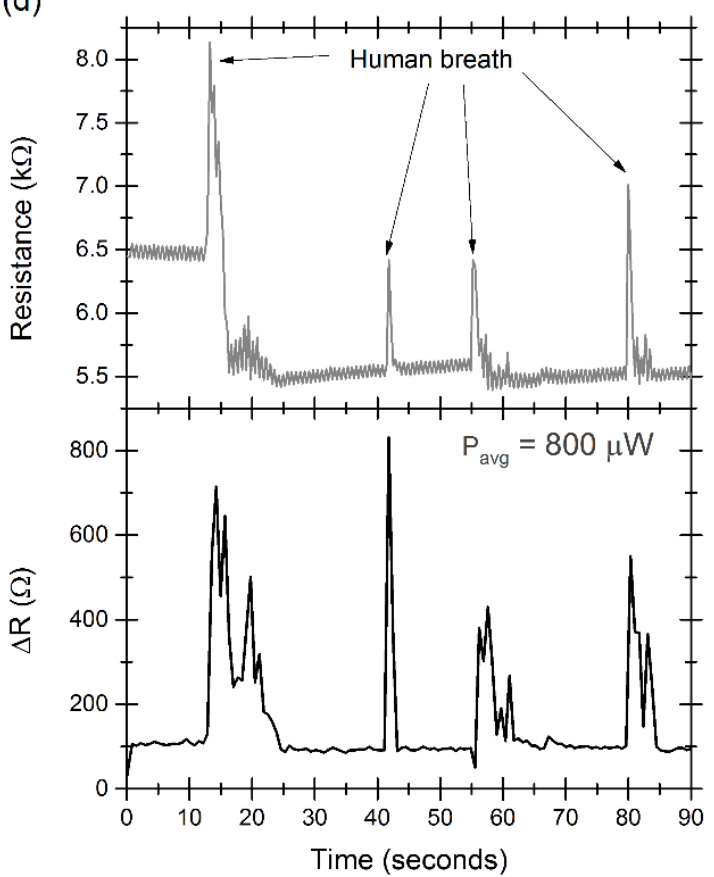

Fig. 12 Test performed with a source-meter unit controlled by a LabVIEW ${ }^{\circledR}$ software. The program compute the $\Delta R$ with a pair of points, both acquired just before the change of sensor operation point and allow in-situ modification of the pulsing conditions to the user. (a) Modification of the high and low voltage levels. (b) Modification of the period. (c) Modification of the signal duty cycle. (d) Detection of human breath in ambient atmosphere. Resistance signal and the computed $\Delta R$ are shown. 


\section{Conclusions}

Pulsed self-heating is a reliable method to extract a highly stable signal only dependent on the gas presence. The methodology successfully removes drifts due to the sensor instabilities, such as chemical surface modification or structural degradation.

With this approach, it is also possible to reduce the power consumption needs down to a few $\mu \mathrm{W}$, in an extremely simple, and cost effective, heater-free configuration.

The pulsed temperatures, the period of the pulse and the duty cycle of the probing signal can be used to modulate the resulting gas sensing response, optimizing response time, response magnitude and power consumption respectively. Whether sensing conditions such as the pulse period could also provide specificity is still an open question.

The presented methodology was used to sense humidity, $\mathrm{NO}_{2}$ and $\mathrm{NH}_{3}$ with carbon based sensors (CNFs sensors), suggesting that the same approach could be extended to other gases and materials, such as metal oxides.

\section{Acknowledgments}

The research leading to these results has received funding from the European Research Council under the European Union's Seventh Framework Programme (FP/2007-2013) / ERC Grant Agreement n. 336917.

J.D. Prades acknowledges the support from the Serra Húnter Programme.

A. Cirera acknowledges support from ICREA Academia program.

\section{Bibliography}

[1] G. Korotcenkov, B.K. Cho, Instability of metal oxide-based conductometric gas sensors and approaches to stability improvement (short survey), Sensors Actuators B Chem. 156 (2011) 527-538. doi:10.1016/j.snb.2011.02.024.

[2] J.L. Figueiredo, M.F.R. Pereira, M.M.A. Freitas, J.J.M. Órfão, Modification of the surface chemistry of activated carbons, Carbon N. Y. 37 (1999) 1379-1389. doi:http://dx.doi.org/10.1016/S0008-6223(98)00333-9.

[3] M. Liess, Electric-field-induced migration of chemisorbed gas molecules on a sensitive film - a new chemical sensor, Thin Solid Films. 410 (2002) 183-187. doi:10.1016/S0040-6090(02)00209-2.

[4] X. Liu, S. Cheng, H. Liu, S. Hu, D. Zhang, H. Ning, A survey on gas sensing technology, Sensors. 12 (2012) 9635-9665. doi:10.3390/s120709635.

[5] D. Vincenzi, M. Butturi, V. Guidi, M. Carotta, G. Martinelli, V. Guarnieri, et al., Development of a low-power thick-film gas sensor deposited by screen-printing 
technique onto a micromachined hotplate, Sensors Actuators B Chem. 77 (2001) 95-99.

[6] D.R. Kauffman, A. Star, Carbon nanotube gas and vapor sensors, Angew. Chemie - Int. Ed. 47 (2008) 6550-6570. doi:10.1002/anie.200704488.

[7] B. Kamp, R. Merkle, R. Lauck, J. Maier, Chemical diffusion of oxygen in tin dioxide: Effects of dopants and oxygen partial pressure, J. Solid State Chem. 178 (2005) 3027-3039. doi:10.1016/j.jssc.2005.07.019.

[8] J.G. McCarty, M. Gusman, D.M. Lowe, D.L. Hildenbrand, K.N. Lau, Stability of supported metal and supported metal oxide combustion catalysts, Catal. Today. 47 (1999) 5-17. doi:10.1016/S0920-5861(98)00279-X.

[9] G. Korotcenkov, V. Brinzari, M. Ivanov, A. Cerneavschi, J. Rodriguez, A. Cirera, et al., Structural stability of indium oxide films deposited by spray pyrolysis during thermal annealing, Thin Solid Films. 479 (2005) 38-51. doi:10.1016/j.tsf.2004.11.107.

[10] P. Wynblatt, G.S. Rohrer, F. Papillon, Grain boundary segregation in oxide ceramics, J. Eur. Ceram. Soc. 23 (2003) 2841-2848. doi:10.1016/S09552219(03)00308-X.

[11] H. Meixner, U. Lampe, Metal oxide sensors, Sensors Actuators B Chem. 33 (1996) 198-202. doi:10.1016/0925-4005(96)80098-0.

[12] H. Esch, G. Huyberechts, R. Mertens, G. Maes, J. Manca, W. De Ceuninck, et al., The stability of Pt heater and temperature sensing elements for silicon integrated tin oxide gas sensors, Sensors Actuators B Chem. 65 (2000) 190-192. doi:10.1016/S0925-4005(99)00301-9.

[13] T.A. Kunt, T.J. McAvoy, R.E. Cavicchi, S. Semancik, Optimization of temperature programmed sensing for gas identification using micro-hotplate sensors, Sensors Actuators B Chem. 53 (1998) 24-43. doi:10.1016/S0925-4005(98)00244-5.

[14] J.D. Fowler, M.J. Allen, V.C. Tung, Y. Yang, R.B. Kaner, B.H. Weiller, Practical chemical sensors from chemically derived graphene., ACS Nano. 3 (2009) 301306. doi:10.1021/nn800593m.

[15] M. Roth, R. Hartinger, R. Faul, H.-E. Endres, Drift reduction of organic coated gas-sensors by temperature modulation, Sensors Actuators B Chem. 36 (1996) 358-362. doi:10.1016/S0925-4005(97)80096-2.

[16] O. Monereo, S. Claramunt, G. Vescio, H. Lahlou, R. Leghrib, J.D. Prades, et al., Carbon nanofiber flexible gas sensor modulated by UV light, in: Solid-State Sensors, Actuator, 2013: pp. 1154-1157.

[17] M.W.G. Hoffmann, A.E. Gad, J.D. Prades, F. Hernandez-Ramirez, R. Fiz, H. Shen, et al., Solar diode sensor: Sensing mechanism and applications, Nano Energy. 2 (2013) 514-522. doi:10.1016/j.nanoen.2012.12.003. 
[18] I. Simon, N. Bârsan, M. Bauer, U. Weimar, Micromachined metal oxide gas sensors: opportunities to improve sensor performance, Sensors Actuators B ... 73 (2001) 1-26.

[19] I.-S. Hwang, E.-B. Lee, S.-J. Kim, J.-K. Choi, J.-H. Cha, H.-J. Lee, et al., Gas sensing properties of $\mathrm{SnO} 2$ nanowires on micro-heater, Sensors Actuators B Chem. 154 (2011) 295-300. doi:10.1016/j.snb.2009.11.012.

[20] J.D. Prades, R. Jimenez-Diaz, F. Hernandez-Ramirez, S. Barth, a. Cirera, a. Romano-Rodriguez, et al., Equivalence between thermal and room temperature UV light-modulated responses of gas sensors based on individual $\mathrm{SnO} 2$ nanowires, Sensors Actuators B Chem. 140 (2009) 337-341. doi:10.1016/j.snb.2009.04.070.

[21] O. Monereo, J.D. Prades, a. Cirera, Self-heating effects in large arrangements of randomly oriented carbon nanofibers: application to gas sensors, Sensors Actuators B Chem. 211 (2015) 489-497. doi:10.1016/j.snb.2015.01.095.

[22] J.D. Prades, R. Jimenez-Diaz, F. Hernandez-Ramirez, J. Pan, A. RomanoRodriguez, S. Mathur, et al., Direct observation of the gas-surface interaction kinetics in nanowires through pulsed self-heating assisted conductometric measurements, Appl. Phys. Lett. 95 (2009) 053101. doi:10.1063/1.3192358.

[23] E. Strelcov, S. Dmitriev, B. Button, J. Cothren, V. Sysoev, A. Kolmakov, Evidence of the self-heating effect on surface reactivity and gas sensing of metal oxide nanowire chemiresistors, Nanotechnology. 19 (2008) 355502. doi:10.1088/0957$4484 / 19 / 35 / 355502$.

[24] J.D. Prades, R. Jimenez-Diaz, F. Hernandez-Ramirez, S. Barth, a. Cirera, a. Romano-Rodriguez, et al., Ultralow power consumption gas sensors based on selfheated individual nanowires, Appl. Phys. Lett. 93 (2008) 123110. doi:10.1063/1.2988265.

[25] J.D. Prades, F. Hernández-Ramírez, T. Fischer, M. Hoffmann, R. Müller, N. López, et al., Quantitative analysis of CO-humidity gas mixtures with self-heated nanowires operated in pulsed mode, Appl. Phys. Lett. 97 (2010) 243105. doi:10.1063/1.3515918.

[26] J.D. Prades, R. Jimenez-Diaz, F. Hernandez-Ramirez, J. Pan, a. RomanoRodriguez, S. Mathur, et al., Direct observation of the gas-surface interaction kinetics in nanowires through pulsed self-heating assisted conductometric measurements, Appl. Phys. Lett. 95 (2009) 93-96. doi:10.1063/1.3192358.

[27] P.H. Rogers, S. Semancik, Feedback-enabled discrimination enhancement for temperature-programmed chemiresistive microsensors, Sensors Actuators, B Chem. 158 (2011) 111-116. doi:10.1016/j.snb.2011.05.051.

[28] A.P. Lee, B.J. Reedy, Temperature modulation in semiconductor gas sensing, Sensors Actuators, B Chem. 60 (1999) 35-42. doi:10.1016/S0925-4005(99)002415. 
[29] L. Fernandez, S. Marco, a. Gutierrez-Galvez, Robustness to sensor damage of a highly redundant gas sensor array, Sensors Actuators B Chem. 218 (2015) 296302. doi:10.1016/j.snb.2015.04.096.

[30] J. Fonollosa, L. Fernández, R. Huerta, A. Gutiérrez-Gálvez, S. Marco, Temperature optimization of metal oxide sensor arrays using Mutual Information, Sensors Actuators, B Chem. 187 (2013) 331-339. doi:10.1016/j.snb.2012.12.026.

[31] Y.A. Kim, T. Hayashi, M. Endo, M.S. Dresselhaus, Carbon Nanofibers, in: Springer Handb. Nanomater., 2013.

[32] O. Monereo, S. Claramunt, M.M. De Marigorta, M. Boix, R. Leghrib, J.D. Prades, et al., Flexible sensor based on carbon nanofibers with multifunctional sensing $\begin{array}{lllll}\text { features., } & \text { Talanta. } & 107 & \text { 239-47. }\end{array}$ http://www.ncbi.nlm.nih.gov/pubmed/23598218.

[33] S. Claramunt, O. Monereo, M. Boix, R. Leghrib, J.D. Prades, A. Cornet, et al., Flexible gas sensor array with an embedded heater based on metal decorated carbon nanofibres, Sensors Actuators, B Chem. 187 (2013) 401-406.

[34] E. Llobet, Gas sensors using carbon nanomaterials: A review, Sensors Actuators B Chem. 179 (2013) 32-45. doi:10.1016/j.snb.2012.11.014.

[35] G. Lu, L.E. Ocola, J. Chen, Gas detection using low-temperature reduced graphene oxide sheets, Appl. Phys. Lett. 94 (2009) 083111. doi:10.1063/1.3086896.

[36] G. Lu, L.E. Ocola, J. Chen, Reduced graphene oxide for room-temperature gas sensors., Nanotechnology. $20 \quad$ (2009) 445502. doi:10.1088/09574484/20/44/445502.

[37] F.M. Ramos, C. López-Gándara, A. Cirera, J.R. Morante, Monolithic Ceramic Technology for Sensing Devices, in: Proc. 2009 Spanish Conf. Electron Devices, 2009: pp. 293-296.

[38] T.R. M. Weisenberger, I. Martín-Gullon, J. Vera-Agullo, H. Varela-Rizo, C. Merino, R. Andrews, D. Qian, The effect of graphitization temperature on the structure of helical-ribbon carbon nanofibers, Carbon N. Y. 47 (2009) 2211-2218.

[39] S. Gomri, J.-L. Seguin, J. Guerin, K. Aguir, Adsorption-desorption noise in gas sensors: Modelling using Langmuir and Wolkenstein models for adsorption, Sensors Actuators B Chem. 114 (2006) 451-459. doi:10.1016/j.snb.2005.05.033.

[40] G. Limousin, J.P. Gaudet, L. Charlet, S. Szenknect, V. Barthès, M. Krimissa, Sorption isotherms: A review on physical bases, modeling and measurement, Appl. Geochemistry. 22 (2007) 249-275. doi:10.1016/j.apgeochem.2006.09.010.

[41] J.D. Prades, R. Jimenez-Diaz, F. Hernandez-Ramirez, a. Cirera, a. RomanoRodriguez, J.R. Morante, Harnessing self-heating in nanowires for energy efficient, fully autonomous and ultra-fast gas sensors, Sensors Actuators B Chem. 144 (2010) 1-5. doi:10.1016/j.snb.2009.09.040. 



\title{
Self-heating in pulsed mode for signal quality improvement: application to carbon nanostructures-based sensors
}

\author{
O. Monereo*, O. Casals, J. D. Prades and A. Cirera \\ MIND-IN²UB, Department of Electronics, University of Barcelona, C/ Martí i Franquès 1, E- \\ 08028 Barcelona, Spain \\ *Corresponding author e-mail: omonereo@el.ub.edu \\ Other authors e-mails: O. Casals (ocasals@el.ub.edu), J.D. Prades (dprades@el.ub.edu), A. Cirera \\ (acirera@el.ub.edu.)
}

\section{Author biographies}

Oriol Monereo was graduated in Physics at the University of Barcelona in 2010 and in Master in Electronic Engineering in 2011. Now he is Ph.D. student in Department of Electronics of the same university. His current research is focused in gas sensors.

Olga Casals was born in Barcelona in 1973. She received her diploma in optics and optometry at the Polytechnic University of Catalonia in 1994, her degree in physics at the University of Barcelona in 2001 and her Ph.D. at the same institution in 2012. Her professional experience is set in development of new technologies on solid-state gas sensors.

Joan Daniel Prades was born in Barcelona in 1982. He graduated in Physics and Electronic Engineering at the University of Barcelona and obtained his Ph.D. at the same institution in 2009. He has experience in modelling of the electronic and vibrational properties of nanostructured metal oxides and in their experimental validation. He is actively involved in the development of innovative device prototypes based on nanomaterials. He has published more than 40 papers in peer-reviewed journals and contributed to more than 100 international conferences. He has also contributed to five industrial patents.

\footnotetext{
Albert Cirera is graduated in Physics (1996) and Ph.D. (2000) by the University of Barcelona. He is currently associate professor of the Electronics Department. He has published more than 60 papers in international journals with more than 1000 cited and $h=19$; as well as more than 100 presentations, 5 book chapters and 5 more patents, he has directed more than 15 industrial and research projects. His current research group deals with computational and applied nanoelectronics, including sensors.
} 